\title{
On the Production of China Universities' Non-Institutionalized Power Structure and the Dialectical Analysis
}

\author{
Yuting Liu \\ Higher Education Institute, Nankai University \\ Tianjin 300071, China \\ E-mail: kaiyun520@gmail.com
}

Received: August 10, 2010 Accepted: January 17, 2011 doi:10.5539/ies.v4n2p102

\begin{abstract}
By analyzing reasons for and problems in China universities' non-institutionalized power structure, this paper tries to prove the limits of non-institutionalized power structure making up for institutionalized power structure in universities, with the hope of revealing the deep reasons for the institutionalized structure imbalance in universities.
\end{abstract}

Keywords: University, Non-institution, Power structure, Production, Analysis

During recent years, more scholars have paid more attention to the institutionalized power structure in universities, that is, the political power under the committee leadership of Communist Party of China, the administrative power under the President-responsibility system, and the academic power under the representative of academic institutions. Few studies focus on analyzing the power structure in universities from the perspective of non-institutionalized structure. How does the non-institutionalized power structure in universities produce? What is the characteristic? This paper aims at probing into these problems further.

\section{The Non-institutionalized Power Structure in China Universities and its Production}

\subsection{The Concept}

Compared with regular and formal institutions, non-institutionalized structure means the "circle" based on interpersonal relations and affections and other informal factors in certain organization. In universities, it mainly refers to the acquisition of projects, the assessment of rewards, the promotion, and social fames.

What is "non-institutionalized power structure"? There is not a clear definition in academic field. Some scholars agree that: "In perspective of theories of organizational sociology, non-institutionalized structure is a space for exchanging emotions and interests based on non-institutionalized rules. It presents a complete set of standard body without established rules for education, by relying on the powers of ethics, traditions, and affections."

The non-institutionalized power structure during certain period in China is a series of "interpersonal relations" formed by the accumulation of institutional structure and values. For the sake of studies, this paper targets at the non-institutional power structure in universities since the foundation of China.

\subsection{The Production of Non-institutionalized Power Structure}

The non-institutionalized power structure in universities is derived from the unreasonable institutional power arrangement in universities. Since the foundation of China, the power structure in universities is institutional, consisting of the political power under the Party's committee leadership, the administrative power under the President-responsibility system, and the academic power with the representative of academic committee.

The "Party's committee leadership" centralized structure has the merits that are in accordance with the needs for early time, that is, "It can guarantee the specialized decision in a sense. And the specialization of decision can assure the rationality of decision. The centralized management is convenient for unified regulation, which can secure the coordinative development of higher education, state polities, and social economy, satisfying the state's needs for higher education."

However, along with the development of times, the shortcomings of institutionalized power structure in universities are prominent. The imbalance of three powers in universities triggers a series of problems in education, such as the "administration-oriented university" issue. With the highly-concentrated management mode, the political power, represented by the central committee of Communist Party of China, the Council, and the Communist Party of China committee of university, not only leads the administrative power and the academic power in a macro aspect, but also 
performs a micro management on them. As a result, the academic institutions, which are supposed to deserving more attentions, tend to be more administrative and official. The academic power strays far away from the central position of power structure in higher education. The former institutionalized mode lost its advantages of being specialized, centralized, and efficient. The merits of power structure in universities are replaced with shortcomings. Then, the non-institutionalized power structure appears.

\section{The Dialectical Analysis of Non-institutionalized Power Structure in China Universities}

First of all, the non-institutionalized structure has its positive aspect: The institutionalized power emphasizes on rules, contracts, and hierarchical structure based on a series of rules. It has rules and serves as an external constraint on individuals. Non-institutionalized power is mainly from thoughts and habits. It is an internal constraint. Therefore, the non-institutionalized power structure is an effective compensation for institutionalized structure: first, it can strengthen the autonomy of running universities, promoting the communication between employees, and reducing barriers for the execution of government policies and regulations. Second, it can improve the consciousness of teachers and students participating into the decision-making and the management.

However, the compensation of non-institutionalized structure for present power structure is limited. It has evident defects in itself, which associates closely with China's social structure and cultural background. In China, the "official standards" is, first of all, a kind of social structure, a giant and serious "official-standard" system founded on two thousand years of Feudalism, which makes the people with powers hold rich sources. Secondly, it is a kind of ideas and values, and a reflection of Feudalism in thoughts ------ The governors stand for the super values of society. Therefore, most people are crazy for an official career, preferring to being a company of governors, or even buying the position with money. Similarly, universities are administrative organizations, in which all positions connect with administration. So, in universities, the "official standards" power structure confirms the values of "official standards". This value misleads teachers and employees pursue for powers in universities.

Non-institutionalized thoughts and styles are not in accordance with real laws. "Latent rule" runs far away from external institutional constraints. The phase "latent rule" is from the popular book Latent rule written by a scholar $\mathrm{Si}$ Wu. Mr. Si Wu explains the meanings of latent rule as: in contrast to "meta rule" and "explicit rules", latent rule is invisible and unwritten clearly, which exert effects widely and gain more acceptances by customs. All people must follow latent rule. The essential reason for the existence of latent rule is the thought of "official standard" in China. University is not an exception. In universities, every power subject prepares for the institutionalized political power, administrative power, and academic power by non-institutionalized "relation net".

The contradictions of non-institutionalized power structure include three aspects as follow:

Firstly, as for the recruitment right concerned, on one hand, universities have the independent recruitment right. Both professors and students can make choices freely. For example, professors hold the right of selecting students. Meanwhile, students have the right of choosing instructors based on self interests. That is from the spirit of academic freedom in universities. On the other hand, the "independent spirit" has been misunderstood. For example, the parents, whose child may miss certain university because of several grades, may bribe the chiefs in the university. Or the parents may ask somebody to "say hello" (present the requirements in fact) to the President of university. All these activities betray the spirits of universities undoubtedly.

Secondly, non-institutionalized power structure can affect the employees' performance assessment, rewards, and promotion. Once somebody builds a strong relation with leaders and gets along well with others, he or she will be more successful in performance assessment, rewards, and promotion. However, in a deeper sense, it is a kind of "non-institutionalized survival", taking interpersonal relations as the media. This mode focuses on powers and money. For example, the "double-shouldering stuff" in universities, including certain Party leaders, holds more resources and powers and gives priorities to their party members in distributing research subjects and funds. In universities of China, the interpersonal net is common, just like outside. People regard "relations" as important tools for surviving in universities.

Thirdly, a positive non-institutionalized college culture can help to get external resources. For example, get more projects or funds, which is helpful to the development of universities. However, with stronger commercial sense, the latent rule tends to be popular in universities. People who can build more relations with the government and companies can win more education resources. Take a case for example. An accounting book can trigger out a series of commercial bribes in universities. Why are more than one hundred employees involved in? It indicates the latent rule in the field of education. Although the Ministry of Education forbids commissions frequently, there is not any written rule concerning this point at present. Therefore, some mangers of universities collect properties by their powers over certain aspects. 
Fourthly, the non-institutionalized power in university focuses on the participation of all power subjects, which promotes the progress of democracy in universities. However, at present the academic power is subject to the political power and the administrative power. In universities, teachers do not possess necessary powers. As a result, more teachers pursue for non-institutionalized protection and support in order to maintain their positions. With the media of money, some teachers build a protect-and-protected relation with the political institutions and the administrative institutions in universities.

In a word, the non-institutionalized power structure is necessary to the institutionalized power structure, which fastens the relation among the academic power, the administrative power, and the political power in universities. As a matter of fact, the imbalance of internal powers in non-institutionalized power structure has already shown the defects, which exerts a negative effect on the institutionalized power structure. The inherent constraints of non-institutionalized power structure drive the communication of universities, reducing barriers to the execution of policies. Meanwhile, non-institutionalized power structure may make laws invalid, giving a priority to the "rule-by-man" over the "rule-by-law".

Therefore, we should not only build a rational and standard power structure for universities, but also create a harmonious mode for both institutionalized power structure and non-institutionalized power structure, making the non-institutionalized power structure exert its advantages completely. For example, use morals to supervise and regulate the political power and the administrative power in universities. And use the college ideas and culture of "academic freedom", "rule-by-professor", and "university autonomy" to make up the defects of institutions.

\section{References}

Xianping, Meng. (2007). An analysis of negative effect of non-systemized survival in the construction of harmonious society and its comprehensive treatment. Journal of Yangtze Normal University. No.4.

Yongjie, Sun. (2009). An investigation on the case of a hundred of universities purchasing books: one accounting book revealing latent rule. [Online] Available: http://news.sina.com.cn/c/2006-07-19/02549502818s.shtml(January 19,2009)

Xuan, Tang. (2007). On Chinese state-owned universities' integration mechanism: from the perspective of governance theory. Doctor Thesis. Wuhan: Wuhan University of Technology. May.

Yan, Wu. (2007). Non-institutionalized structure: the second incentive system. Vocational and Technical Education. No.10.

Bingqi, Xiong. (2004). Universities Have Problems. Chengdu: Tiandi Publishing House. p136-140

Tianxiang, Xue. (2006). High Education Management. Guilin: Guangxi Normal University Press. p142. 